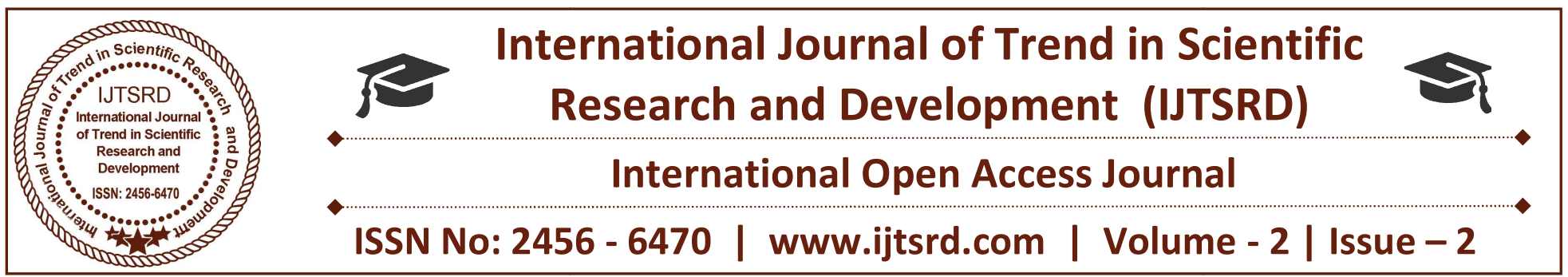

\title{
IoT - Internet of Things Based Energy Management for Smart Home
}

\author{
R. Nareshkumar, B. J. Naveenkumar, R. Sivasankari \\ Department of Computer Science and Engineering, G.K.M. \\ College of Engineering and Technology, Chennai, Tamil Nadu, India
}

\begin{abstract}
This paper presents an idea or a concept for smart home using mobile application. Today, smart home industry is growing widely; this is powered by the need to provide systems, which provides support for aged and physically handicapped people, especially people who lives alone. Smart home or home automation can be said as the residential extension of building automation, it also involves the automation and controlling of lightings, ACs, ventilation and security which also includes home appliances such as dryers/washers, ovens or refrigerators/freezers which uses Wi-Fi for monitoring via remote. Smart Home must have compliance with all the household standards and ease of use. This paper focuses on flexible, cost friendly wireless smart home system, which would be based on an Android App. The app will be working with the help of node mcu ESP8266 and firebase also Internet of Things. The App would be featuring the process of mobile app that would be taking commands from user in order to control different home appliances that would be connected via IOT.
\end{abstract}

Keywords: E-Controller, E-metering, Android application, Google firebase, IOT internet of things, node mcu ESP8266

\section{INTRODUCTION}

Electricity has become one of many necessities of our everyday life. The right use of electric energy is very important to provide this valuable resource to as many people as possible. The efficient use of electric energy is highly dependent on energy metering. This paper presents an idea or a concept for smart home. Smart home or home automation can be said as the residential extension, it also involves the automation and controlling of lightings, ACs and security, which includes other home appliances which uses Wi-Fi for monitoring. Data is collected with the help of node mcu ESP8266 and Firebase. The main aim of the project is to replace the existing manual reading of electricity meters installed throughout the country. The proposed project is designed for reading Electrical energy in units and view in Mobile Application to the customer's mobile.

\section{RELATED WORKS}

A Rohit Bhilare and Shital Mali (2015) IoT Based Smart Home with Real Time E-Metering using Econtroller they used the web application to control the power in energy meter. A Frank Englert, Patrick Lieser, Alaa Alhamoud, Doreen Boehnstedt, Ralf Steinmetz (2015) Electricity-Metering in a Connected World: Virtual Sensors for Estimating the Electricity Consumption of IoT Appliances. This project is based on some inputs using additional sensors for estimating the electricity consumption. Ming Wang, Guiqing Zhang, Chenghui Zhang, Jianbin Zhang, Chengdong Li (2013) They used wireless sensor to monitor whole home, developed an IoT-based Appliance Control System for Smart Homes. To manage all appliances in a smart home, it is necessary to develop a smart home information system (SHIS), which can be running in a management sever or the owner's computer. Smart Home: Integrating Internet of Things with Web Services and Cloud Computing (2015) Moataz Soliman1, Tobi Abiodun1, Tarek Hamouda, Jiehan Zhou, Chung-Horng Lung1 the project was used to some cloud storage to the web services to control the 
devices. Exploiting IoT-based Sensed Data in Smart the project used small computers called as Raspberry Buildings to Model its Energy Consumption (2015) pi for the webserver to control the for home M. Victoria Moreno and Antonio F. Skarmeta_Luc Dufoury, Dominique Genoudy and Antonio J. Jaray This project sense the data in smart buildings to model its Energy consumption by using IoT devices. IoT based Monitoring and Control System for Home Automation (2015) Pavithra.D Ranjith Balakrishnan automation. An IoT based Home Automation Using Android Application (2016) P.Siva Nagendra Reddy, K.Tharun Kumar Reddy, P.Ajay Kumar Reddy, Dr.G.N.KodandaRamaiah, S.Nanda Kishore this project was used to control the bulb and fan devices to the brightness and speed by using android application.

\section{PROPOSED SYSTEM}

This project is designed with additional features in the existing system such that it is planned to add some IOT devices to control the electricity and monitoring purpose.

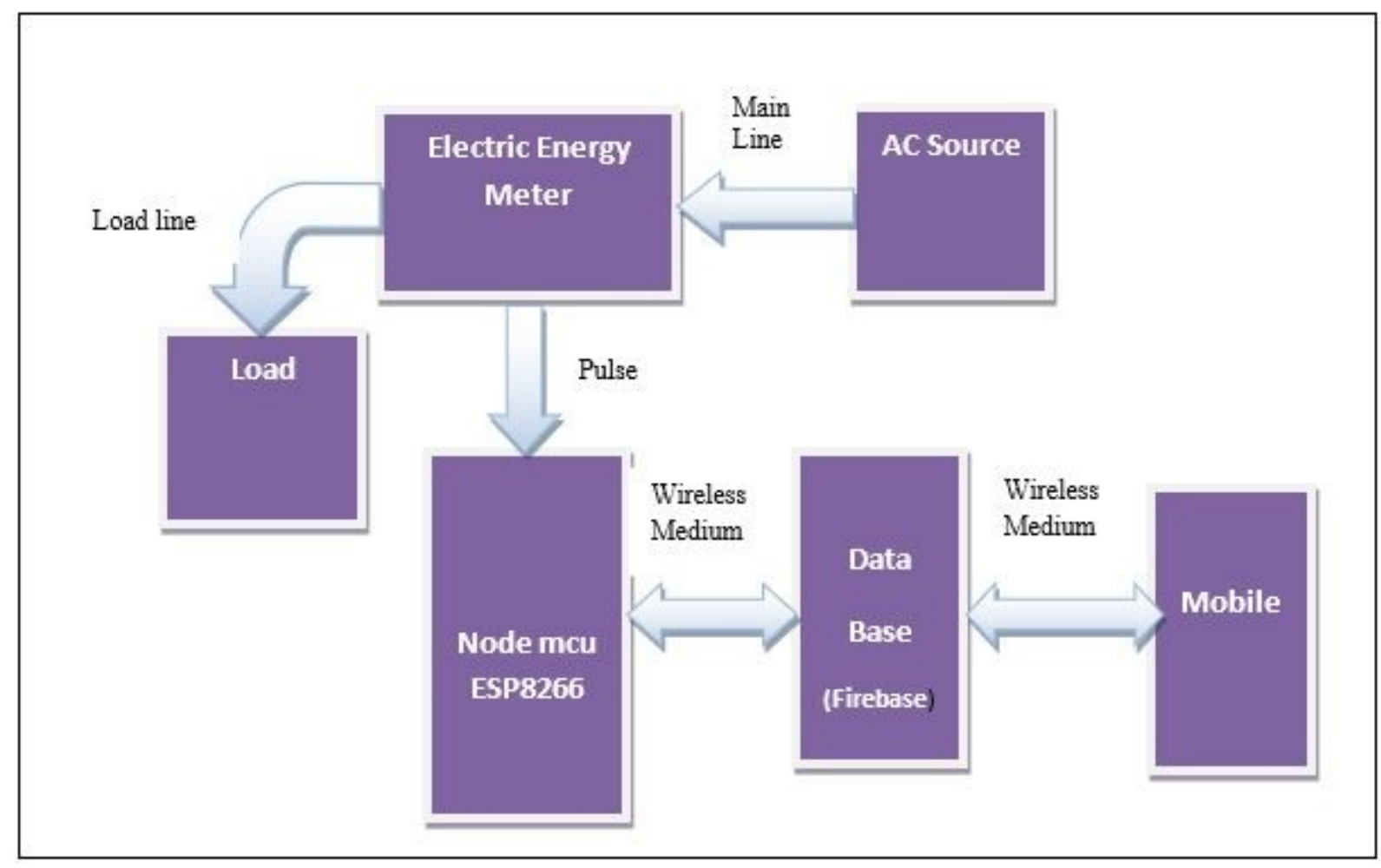

Fig 1: General Block Diagram

\section{Hardware Phase}

\section{Node mcu esp 8266}

This micro controller is used as server, which gives the readings of electrical pulses from the electric meter, and further it delivers that value to the database, from that we can use those values are used further process.

\section{Energy meter}

The digital energy meter is used to calculate the pulses from the load that is given to the process. 


\section{Storage Phase}

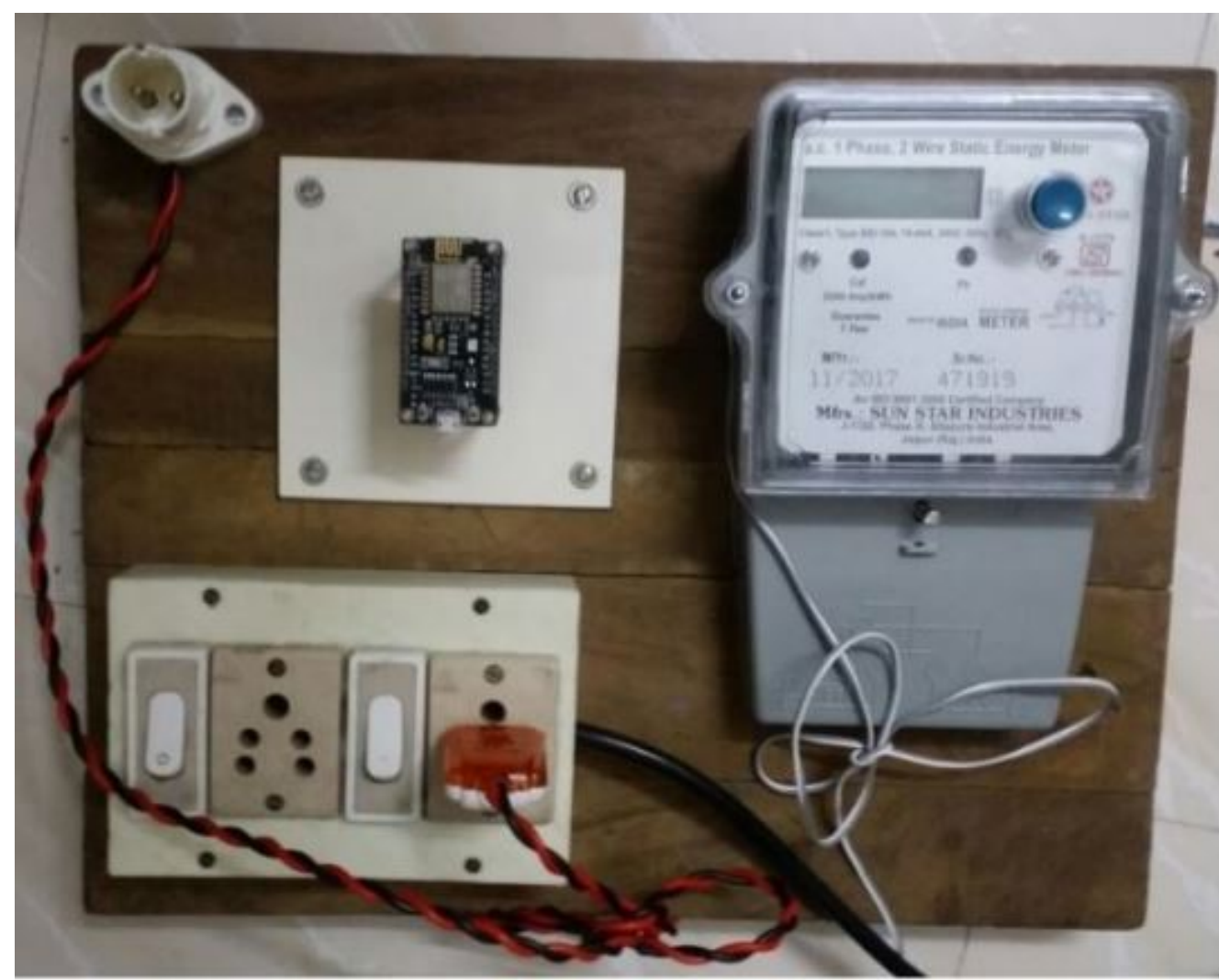

\section{Fig 2}

For storing and retrieving the data we used Google's firebase is used

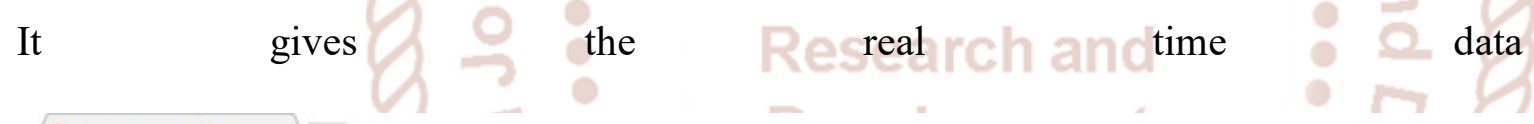

reliable.

b) Energy meter using sma $x$

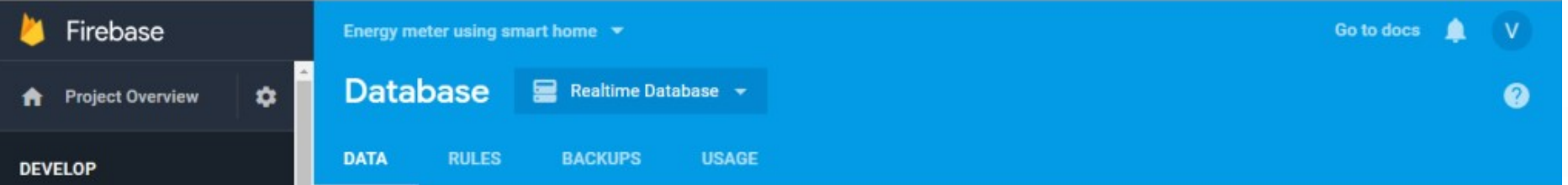

a. Authentication

르 Database

A Storage

(3) Hosting

(-.) Functions

STABILITY

: Crashlytics

* Crash Reporting

(2) Performance

Spark

Free \$0/month

UPGRADE

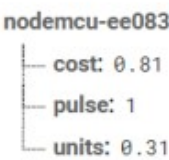

nodemcu-ee083

L cost: 0.81

- pulse: 1

Lunits: 0.31

H $O$ Type here to search

Fig. 3 


\section{Software Phase}

\section{Arduino IDE}

This software is used to convert the pulses into units and predict the cost. And also it is used to communicate with database.

Embedded $\mathrm{C}(\mathrm{C} / \mathrm{C}++)$ is used for this work

\section{Android Studio}

An android application is created for easily communicate on with electrical appliances. It shows the real time energy readings.

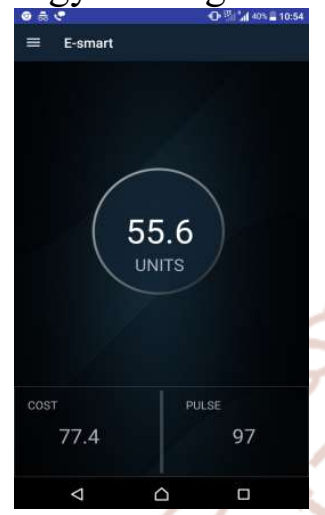

Fig. 4

Information Processing (ICICIP), 2013 Fourth International Conference on (pp. 744-747). IEEE.

2. Soliman, M., Abiodun, T., Hamouda, T., Zhou, J. and Lung, C.H., 2013, December. Smart home: Integrating internet of things with web services and cloud computing. In Cloud Computing Technology and Science (CloudCom), 2013 IEEE 5th International Conference on (Vol. 2, pp. 317320). IEEE.

3. Bhilare, R. and Mali, S., 2015, December. IoT based smart home with real time E-metering using E-controller. In India Conference (INDICON), 2015 Annual IEEE (pp. 1-6). IEEE.

4. Englert, F., Lieser, P., Alhamoud, A., Boehnstedt, D. and Steinmetz, R., 2015, August. Electricity Metering in a Connected World: Virtual Sensors for Estimating the Electricity Consumption of IoT Appliances. In Future Internet of Things and Cloud (FiCloud), 2015 third International Conference on (pp. 317-324). IEEE.

5. Moreno, M.V., Skarmeta, A.F., Dufour, L., Genoud, D. and Jara, A.J., 2015, June. Exploiting IoT-based sensed data in smart buildings to model its energy consumption. In Communications (ICC), 2015 IEEE International Conference on (pp. 698-703). IEEE.

This project uses only simple components and is more reliable. Less power consuming microcontroller is used and moreover it does not use any costly ICs or circuits. Not only do people can see how much they have consumed, they can also control their appliances using IoT, which serves as an added advantage. By installing this project in commercial households, people can get an idea of how much energy they are consuming in real time. By setting a pre-set cost, they can limit their use of resources and thus able to save cost and energy efficiently. With the advancements in technology, there should not be any problem in connectivity of internet in the residential areas. If the people are not at their homes and if they forgot to turn off any equipment, they can easily control it from anywhere in the world with a computer/mobile phone with an internet connection. The data in the google firebase cloud provides detailed consumption of power in a particular day, month or a year. By this way, they can manage energy by knowing where they are consuming the energy more. Hence, this project serves as an effective tool for energy monitoring and management.

\section{REFERENCES}

1. Wang, M., Zhang, G., Zhang, C., Zhang, J. and Li, C., 2013, June. An IoT-based appliance control system for smart homes. In Intelligent Control and

6. Pavithra, D. and Balakrishnan, R., 2015, April. IoT based monitoring and control system for home automation. In Communication Technologies (GCCT), 2015 Global Conference on (pp. 169-173). IEEE.

7. "Deore, R.K., Sonawane, V.R. and Satpute, P.H., 2015, December. Internet of Thing Based Home Appliances Control. In Computational Intelligence and Communication Networks (CICN), 2015 International Conference on (pp. 898-902). IEEE.

8. Reddy, P.S.N., Reddy, K.T.K., Reddy, P.A.K., Ramaiah, G.K. and Kishor, S.N., 2016, October. An IoT based home automation using android application. In Signal Processing, Communication, Power and Embedded System (SCOPES), 2016 International Conference on (pp. 285-290). IEEE.

9. Ashok, M., Varma, P.S. and Sundari, M.R., 2017. IoT based Monitoring and Control System for Home Automation

10. Giaconi, G., Gündüz, D. and Poor, H.V., 2018. Smart Meter Privacy with Renewable Energy and an Energy Storage Device. IEEE Transactions on Information Forensics and Security, 13(1), pp.129-142. 